\title{
Ascorbate in the apoplast of elongating plant cells
}

\section{Elena Sharova and Aleksandra Romanova}

Department of Plant Physiology and Biochemistry, Faculty of Biology, Saint Petersburg State University, Universitetskaya nab., 7-9, Saint Petersburg, 199034, Russian Federation

Address correspondence and requests for materials to Elena I. Sharova, elenasharova@mail.ru

\begin{abstract}
It was shown that basipetal retardation of cell elongation in the growth zone of etiolated maize mesocotyls correlates with a steep decrease in the apoplastic ascorbic acid (ASC) concentration $(50 \mu \mathrm{M} \rightarrow 10 \mu \mathrm{M})$ and ascorbate redox state $(17 \% \rightarrow 5 \%)$. Exogenous ASC $(0.3 \mathrm{mM})$ not only inhibits peroxidase-dependent oxidation of phenols in vitro. It also exerts a highly specific effect on the secretion of peroxidases by stimulating the release of some isoforms while inhibiting the release of others to the cell walls. This effect points to the hypothetic signaling function of apoplastic ascorbate. Previously, we described a basipetal decrease in hydrogen peroxide concentration in the apoplast (from 5.1 to $2.0 \mu \mathrm{M}$ ) and a two-times increase in cell wall peroxidase potential activity (Sharova et al., 2012). Summarizing found gradients, we can assume that the conditions in the apoplast of the upper mesocotyl segment are favorable for the occurrence of the Fenton reaction (high ASC and hydrogen peroxide concentrations) and unfavorable for the oxidation of phenols (high ASC concentration and low potential peroxidase activity), which contributes to cell wall extensibility and rapid cell elongation.
\end{abstract}

Keywords: apoplast, ascorbate, cell wall, growth regulation, maize seedlings, peroxidase, secretion

\section{Introduction}

Citation: Sharova, E. and Romanova, A. 2018. Ascorbate in the apoplast of elongating plant cells. Bio. Comm. 63(1): 77-86. https://doi.org/10.21638/ spbu03.2018.109

Author's information: Elena I. Sharova, Ph.D., Assoc. Professor, orcid.org/00000003-2746-1993, Researcher ID: P-1695 2014; Alexandra S. Romanova, student

Manuscript Editor: Farida Minibayeva, Kazan Institute of Biochemistry and Biophysics, Kazan, Russia;

Guest Editor: Maria Shishova, Saint Petersburg State University, Saint Petersburg, Russia;

Received: December 25, 2017;

Revised: April 24, 2018;

Accepted: April 26, 2018;

Copyright: @ 2018 Sharova and Romanova. This is an open-access article distributed under the terms of the License Agreement with Saint Petersburg State University, which permits to the authors an unrestricted distribution and self-archiving free of charge.

Funding: No funding information have been provided.
The fast growth of plants is achieved by the mechanism of cell extension growth. At the extension stage, which lasts from several hours to several days, plant cells osmotically absorb water, form a central vacuole with a high concentration of osmotically active substances, and hugely increase in size. Over the long history of growth investigation, it has been firmly established that regulation of growth rate mainly occurs through modifications in cell walls' extensibility. However, mechanisms regulating the extensibility remain largely unknown. Plant cell walls are not an inert layer of cellulose, hemicellulose and pectins. Many different proteins are localized in muro, and hundreds of reactions, spontaneous and catalyzed by enzymes, take place there. Metabolism of cell walls is strongly dependent on continuous secretion of proteins, polysaccharides, sugars, organic and amino acids, and various phenolic compounds. In the cell walls, many of these compounds participate in hydrolytic and oxidative reactions. According to modern concepts, some of these reactions make it possible to rapidly increase (or decrease) wall extensibility and thus rapidly accelerate (or decelerate) cell extension (Sharova, 2004).

Ascorbic acid is the only representative of the "Big Three" of biological reductants - NAD $(\mathrm{P}) \mathrm{H}$, glutathione, and ascorbate - which is present at considerable amounts in cell walls (Sharova, 2016; Sharova and Medvedev, 2017). The apoplast contains $2-8 \%$ of total cellular ascorbate, where its concentration is $0.1-1 \mathrm{mM}$ (Ueda 
et al., 2013). Inside cells, nearly $90 \%$ of the ascorbate exists in a reduced form (ASC), whereas the ratio of ASC to dehydroascorbate (DHA) in cell walls strongly varies from 0 to $60-70 \%$. In cell walls, ASC transported from the cytoplasm is oxidized through PRX, ascorbate peroxidase, ascorbate oxidase activities, as well as nonenzymatically by $\mathrm{Fe}^{3+}, \mathrm{Cu}^{2+}$, or reactive oxygen species (ROS).

Class III heme-containing peroxidases or so-called guaiacol peroxidases (PRX) are the most numerous and active oxidoreductases located in the cell walls (Sharova and Medvedev, 2017). These enzymes are involved both in ROS-consuming and ROS-generating reactions. Plants contain a large number of PRX genes, for example, 73 in the Arabidopsis (Cosio and Dunand, 2009). And due to glycosylation, the number of peroxidase isoenzymes in cell walls is even greater. In the course of the peroxidase catalytic cycle, enzyme (E) is first oxidized by hydrogen peroxide $\left(\mathrm{H}_{2} \mathrm{O}_{2}\right)$ and turns into Compound $\mathrm{I}-\mathrm{E}(\mathrm{O})$. After two sequential one-electron oxidations of the substrate, the enzyme converts into Compound $\mathrm{II}-\mathrm{E}\left(\mathrm{O}^{-}\right.$ ) - and then returns to its ground state. PRXs mainly oxidize phenolic compounds to phenoxyl radicals and exhibit low substrate specificity. Phenoxyl radicals usually dimerize, forming phenolic bridges that reduce cell wall extensibility. PRXs display not only peroxidase but also oxidase activity coupled with generation of ROS (Heyno et al., 2011). In vitro, PRXs display the maximum oxidase activity towards $\mathrm{NAD}(\mathrm{P}) \mathrm{H}$, which, in the presence of $\mathrm{Mn}^{2+}$ and phenolic cofactors, is oxidized following the total equation $\mathrm{NAD}(\mathrm{P}) \mathrm{H}+\mathrm{O}_{2} \rightarrow \mathrm{NAD}(\mathrm{P})^{+}+\mathrm{H}_{2} \mathrm{O}_{2}$ (HadziTaskovic-Sukalovic et al., 2008; Kukavica et al., 2009).

Relations between cell growth rate and PRX activities in cell walls have been studied over many decades (Francoz et al., 2015). Progressive basipetal retardation of cell elongation along shoots and roots growth regions is usually accompanied by a considerable accumulation of PRXs in cell walls (Dragisic-Maksimovic et al., 2008; Sharova et al., 2012). Similar PRX accumulation is often observed during growth retardation under stress conditions (Uddin et al., 2014). The function of PRXs in growth suppression is explained by the enzymatic catalysis of oxidative cross-links and lignin synthesis (Shigeto et al., 2014). All the same, PRXs that are mainly localized in rapidly expanding cell walls exist as well. Such PRXs were discovered by proteome analysis in cell walls of maize root tips (Zhu et al., 2007). In an emerging hair of a cotton seed, a positive correlation between growth rate, ROS formation, and PRX GhPOX1 activity is observed (Mei et al., 2009). PRX inhibitor (salicylhydroxamic acid) suppresses both hair elongation and ROS generation. In Arabidopsis, enzymes prx33 and 34, capable of ROS production, are apparently involved in root growth maintenance (Passardi et al., 2006). Mutations in these PRXs lead to shorter roots, while roots of overexpessors are longer than in a wild type.
PRXs do not oxidize ASC in the absence of phenolic compounds (Sanchez et al., 1997). ASC is oxidized in the peroxidase reaction because it reduces phenoxyl radicals (Hadzi-Taskovic Sukalovic et al., 2008). Consequently, while ASC is present in the reaction medium, the oxidation of phenols does not occur. Thus, apoplastic ASC prevents lignification and formation of phenolic crosslinks between wall polymers (Takahama, 1993; Sanchez et al., 1997; Padu, 1999). Ascorbate peroxidase activity in cell walls is negligible (Sharova and Medvedev, 2017). Therefore, excepting PRX, only ascorbate oxidases significantly contribute to the metabolism of ascorbate in the cell walls. However, ascorbate oxidases activity, in contrast to PRX activity, varies greatly in plants of different taxa. They are the most active in Cucurbitaceae and Solanaceae (De Tullio et al., 2013).

Modern concepts explaining the role of apoplastic ASC in growth regulation are based on its ability to suppress the oxidation of phenolics by peroxidases in vitro, on information about the content of ASC and DHA in the apoplast of growing cells, on the correlation between growth rate and ascorbate oxidase activity, and on the effects of treating growing tissues and isolated cell walls with exogenous ASC and DHA. The substantial evidence of apoplastic ascorbate participation in the regulation of cell elongation rests on studies of ascorbate oxidase activity. It is at its highest during cell elongation in tobacco suspension culture (Kato and Esaka, 1999). It increases in Arabidopsis roots upon their gravistimulation (Lee et al., 2011). In addition, ascorbate oxidase (AO) activity and expression of the $\mathrm{AO}$ encoding genes are enhanced many times upon exposure to auxin (Kisu et al., 1997). The study of transgenic tobacco plants with a different expression level of AO implies that the ASC/DHA ratio in the apoplast can be perceived by redox-sensitive receptors of the plasma membrane as a signal regulating gene expression, synthesis and secretion of proteins (Pignocchi and Foyer, 2003).

Information about ascorbate content in the apoplast of growing tissues is scarce and contradictory. For example, in a series of works, Takahama and his collaborators compared the dynamics of ASC and DHA in the apoplast with the elongation rate of excised adzuki bean epicotyl segments (Takahama, 1994; Takahama and Oniki, 1994; Takahama, 1996). The authors came to the conclusion that rapid growth corresponds to relatively high ASC + DHA content and a relatively low ASC/(ASC + DHA) ratio in the apoplast. The determination of ASC and DHA in the apoplast of pine hypocotyles (Sanchez et al., 1997) and peas epicotyls (De Pinto and De Gara, 2004) showed that the fastest-growing segments have more ASC + DHA and a higher ratio ASC/(ASC + DHA) than slow-growing segments. The evaluation of these characteristics along onion roots gave the opposite results: in root tips, where cell division and elongation 
occur, ASC+ DHA and the ASC/(ASC+DHA) ratio were lower than in the apoplast of distal root zones (Cordoba-Pedregosa et al., 2003). In vitro, ascorbate can exhibit pro-oxidant properties. Hydroxyl radicals are produced in the mixture of ascorbate, copper ions and hydrogen peroxide. Treatment of cell walls with this mixture dramatically increases their extensibility (Schopfer, 2001). Correspondingly, it was shown that stimulation of cell growth by exogenous ASC takes place only if the ASC is rapidly oxidized, for example, in the presence of $\mathrm{Cu}^{2+}$ or $\mathrm{H}_{2} \mathrm{O}_{2}$ (Gonzalez-Reyes et al., 1995; Cordoba-Pedregosa et al., 1996). Usually the treatment of growing tissues with ASC either does not affect elongation or suppresses it (Tyburski et al., 2012; Qian et al., 2014).

Overall, the role of apoplastic ascorbate in growth regulation remains unclear. Ascorbate is the most important indicator of redox balance in the cell walls, while peroxidases are the key oxidoreductases of this cell compartment. It can be assumed that the effect of ascorbate on peroxidases is not confined only to direct suppression of peroxidase-dependent phenolics oxidation. Therefore, we studied the effect of ascorbate on the secretion of peroxidases into the cell walls. We also evaluated ASC and DHA content in the apoplast of cells with different growth rates to determine the correlation between these characteristics.

\section{Materials and Methods}

\section{PLANT GROWTH CONDITIONS}

The research was carried out with coleoptiles and mesocotyls of 4-day-old maize (Zea mays L., var. NART-150) seedlings grown in the dark at $27^{\circ} \mathrm{C}$ (Fig. 1). To assess growth rate, mesocotyls were marked with Chinese ink at $5 \mathrm{~mm}$ intervals starting from $1.5 \mathrm{~mm}$ below the coleoptile node. Subapical coleoptile segments were cut $4 \mathrm{~mm}$ below the tip, peeled with forceps to remove cutinized epidermis and recut to the final length of $10 \mathrm{~mm}$. Removal of cutinized epidermis provided free diffusion of peroxidases from cell walls to the incubation medium. We previously showed that this process reflects the secretory activity of the protoplast, because inhibitors of vesicular secretion monensin $\left(10^{-7} \mathrm{M}\right)$ quickly and strongly reduced the release of peroxidases to the medium (Sharova, 2003).

\section{DYNAMICS OF PEROXIDASE SECRETION}

Coleoptile segments were preincubated in a large volume of a basal incubation solution $(2 \mathrm{mM} \mathrm{K}$-citratephosphate buffer, $\mathrm{pH} 6.0,0.5 \mathrm{mM} \mathrm{CaCl}, 10 \mathrm{mg} / \mathrm{l}$ streptomycin, $10 \mathrm{mg} / \mathrm{l}$ penicillin) for $4 \mathrm{~h}$ before the beginning of experimental treatment with $0.3 \mathrm{mM}$ ASC. Then segments were incubated in a small volume of solution.

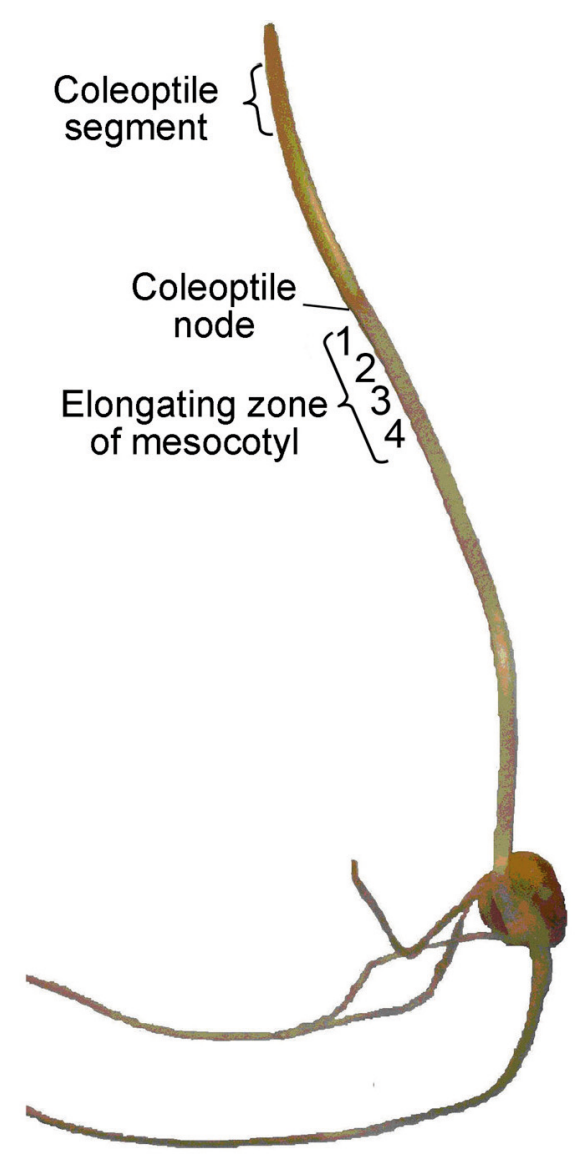

Fig. 1. 4-day-old etiolated maize seedling. Coleoptile and mesocotyl segments used in the research are marked with parentheses.

Each sample contained 150 segments in $10 \mathrm{ml}$ solution, which was replaced with fresh solution every hour. The removed solution was concentrated up to $40 \mu \mathrm{l}$ by dialysis - first, against polyethylene glycol $(40 \mathrm{kD})$, then against sucrose. Concentrated samples were used for electrophoretic fractionation of peroxidases.

\section{ELECTROPHORETIC FRACTIONATION, STAINING AND SCANNING OF PRX ISOZYMES}

To separate PRX isozymes, non-denaturing electrophoresis was performed on $7.5 \%$ polyacrylamide gels (PAG) in alkaline (Davis, 1964) and acidic (Reisfeld et al., 1962) buffers. Peroxidases in PAG were revealed during 30-40 min incubation in a staining mixture containing $100 \mathrm{mM} \mathrm{Na}$-acetate buffer, $\mathrm{pH}$ 5.0, $35 \mathrm{mM}$ guaiacol, $3.5 \mathrm{mM} \mathrm{H}_{2} \mathrm{O}_{2}$. PAG scanning and quantitative processing was carried out on a ChemiDoc ${ }^{\mathrm{mm}} \mathrm{MP}$ gel imaging System with Image $\mathrm{Lab}^{\mathrm{Tw}}$ software from Biorad.

\section{EXTRACTION OF APOPLASTIC FLUID}

Apoplastic fluid was obtained by low-speed centrifugation. Mesocotyls were cut into four (1-4) consecutive 5-mm-long segments (250-300 segments, 2.7-3.3 g in 
each sample) starting from $1.5 \mathrm{~mm}$ below the coleoptile node. Segments were blotted dry and placed into the barrels of plastic syringes $(20 \mathrm{ml})$ inserted in centrifuge tubes. The segments were centrifuged at $10^{\circ} \mathrm{C}$ for $10 \mathrm{~min}$ at $1700 \mathrm{~g}$ using MPW-350R centrifuge. When centrifugation was over, the barrel with the segments was removed from the tube, and a drop (90-120 $\mu \mathrm{l})$ of apoplastic fluid released from the segments was collected from the tube bottom. Apoplastic fluid was tested for cytoplasmic contamination by the activity of glucose 6-phosphate dehydrogenase in a reaction mixture of the following composition: $2.0 \mathrm{ml}$ of glycylglycine buffer, pH $7.5(80 \mathrm{mM}), 0.2 \mathrm{ml}$ of magnesium acetate $(100 \mathrm{mM}), 0.1 \mathrm{ml}$ of NADP $(15 \mathrm{mM}), 0.4 \mathrm{ml}$ of glucose 6-phosphate $(40 \mathrm{mM}), 0.1 \mathrm{ml}$ of apoplastic fluid or the extract from plant tissue. The reaction was conducted at room temperature. An increase in extinction caused by production of NADPH was measured at $340 \mathrm{~nm}$ using NanoPhotometer IMPLEN P300. Enzyme activity was calculated using NADPH specific extinction $\varepsilon_{340}=$ $6.22 \mathrm{mM}^{-1} \mathrm{~cm}^{-1}$ and expressed per $1 \mathrm{~g}$ fresh weight of the tissue that was homogenized or centrifuged for the extraction of apoplastic fluid.

To prevent ASC oxidation, the apoplastic fluid destined for ASC and DHA measurements was fixed in metaphosphoric acid. To this end, before centrifugation $130 \mu \mathrm{l}$ of $6 \%$ metaphosphoric acid was placed at the bottom of every centrifuge tube.

\section{ASC AND DHA MEASUREMENT}

This method is based on direct spectrometric measurement as described by Ueda et al. (2013). The measurements were performed on the NanoPhotometer IMPLEN P300. The apoplastic fluid fixed in metaphosphoric acid was diluted with distilled water to the final volume of $260 \mu \mathrm{l}$. The total ascorbate (ASC + DHA) was determined with the use of dithiotreitol (DTT). The method is based on two processes. First, ASC is quickly oxidized after alkalinization of the sample to $\mathrm{pH} 7.8$. Second, DTT (4 mM in the reaction mixture) quickly reduces DHA in the alkaline medium. Therefore, the difference of optical densities (OD) of samples \pm DTT makes it possible to calculate ASC + DHA using ASC specific extinction $\varepsilon_{267}=14.3 \mathrm{mM}^{-1} \mathrm{~cm}^{-1}$.

ASC was measured using ascorbate oxidase (EC 1.10.3.3, Sigma ascorbate oxidase from Cucurbita, $1-3 \mathrm{kU} / \mathrm{mg}$ protein). First, lyophilized ascorbate oxidase was dissolved in $25 \mathrm{mM} \mathrm{K}$-phosphate buffer ( $\mathrm{pH} 5.8$ ) with $40 \%$ glycerol to obtain a $1.0 \mathrm{U} / \mu \mathrm{l}$ stock solution which was stored at $-10^{\circ} \mathrm{C}$. Before measurement, the stock solution was diluted by 10 times with $100 \mathrm{mM} \mathrm{K}$ phosphate buffer (pH 5.8). A sample of acid-fixed apoplastic fluid was adjusted to $\mathrm{pH} 5.8$ with $1 \mathrm{~N} \mathrm{KOH}$ before the addition of ascorbate oxidase $(1.5 \mathrm{U} / \mathrm{ml}$ in the final volume). The decrease in OD at $265 \mathrm{~nm}$ due to ASC oxidation was monitored for $1 \mathrm{~min}$.

The data were statistically treated using Microsoft Excel. The presented values are the means of four independent experiments \pm SE.

\section{Results}

THE EFFECT OF ASC ON APOPLAST PEROXIDASE ACTIVITY IN VITRO AND IN VIVO

At first, we investigated ASC effect on the total apoplastic peroxidase activity in vitro. This allowed us to choose the optimal working concentration of ASC and to obtain the necessary information for further analysis of its action in vivo. For further experiments we chose $0.3 \mathrm{mM}$, which is only several times higher than reported ASC concentration in the apoplast (Sharova and Medvedev, 2017). At this concentration ASC strongly inhibited peroxidase activity in vitro (Fig. 2). The process of inhibition consisted of two phases. In the first phase ASC completely blocked peroxidase-catalyzed oxidation of the model substrate guaiacol. This lag-phase lasted 30$50 \mathrm{~min}$, depending on the enzyme content in the sample. In the next phase peroxidase started to oxidize guaiacol, but the reaction rate was two to three times lower than the control one. Within six hours of incubation, ASC $(0.3 \mathrm{mM})$ had no significant effect on elongation of coleoptile segments (data are not shown), although, judging by the reaction in vitro (Fig. 2), oxidation of phenols in the cell walls was heavily suppressed. It can be assumed that the effect of ASC in vivo is more complex, in particular, that it not only affects processes in the cell walls, but also touches intracellular processes. A sharp change in the redox balance of the cell walls in the presence of exogenous ASC could be a signal, leading in particular to increased secretion of peroxidases.

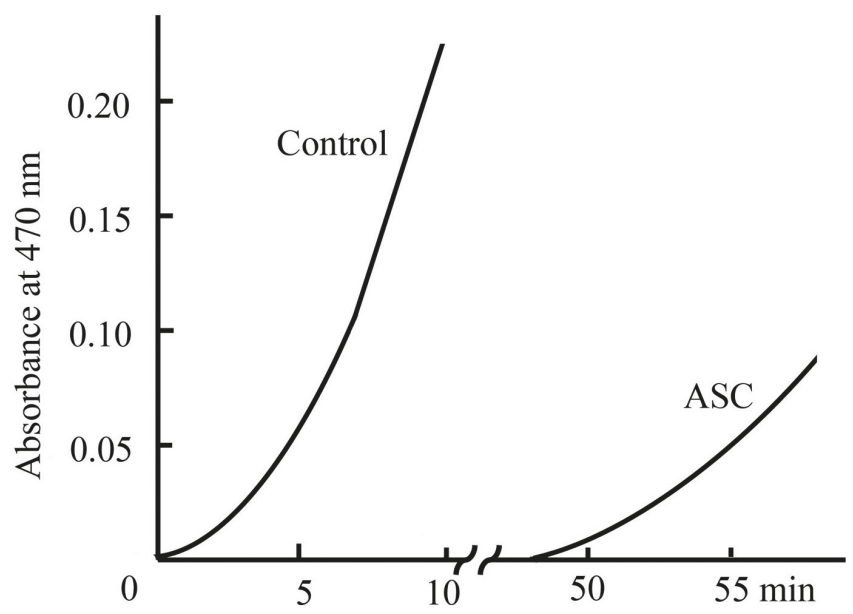

Fig. 2. ASC influence on PRX activity in vitro. Reaction mixture consists of PRX released from coleoptile segments to the medium, $20 \mathrm{mM} \mathrm{Na}$ acetate buffer ( $\mathrm{pH} 5.0), 35 \mathrm{mM}$ guaiacol, $3.5 \mathrm{mM} \mathrm{H}_{2} \mathrm{O}_{2}$, and $0.3 \mathrm{mM}$ ASC (where indicated). 

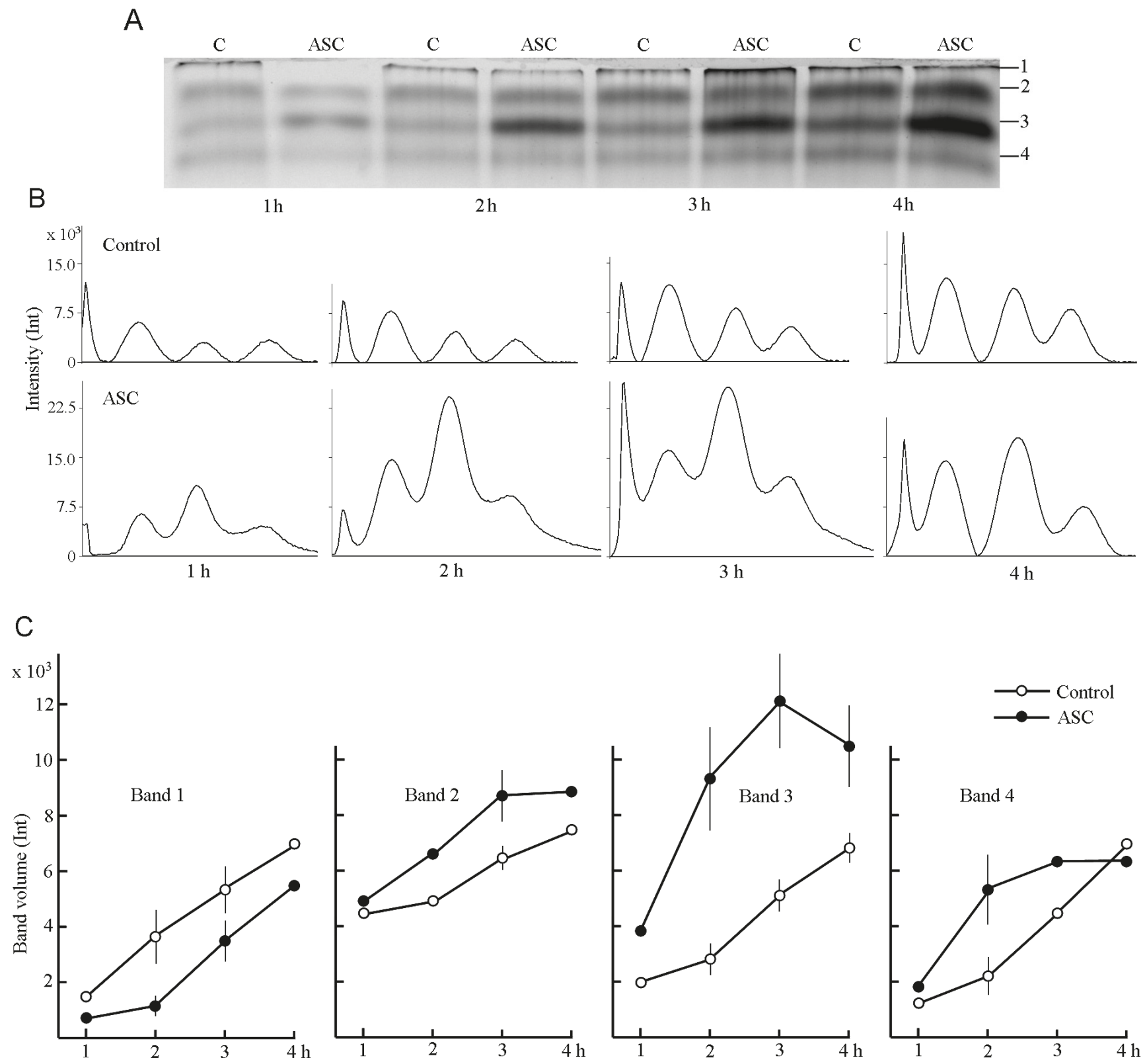

Fig. 3. ASC (0.3 mM) influence on anionic isoperoxidase secretion. A. Peroxidase isozymes revealed in polyacrylamide gels after electrophoresis according to Davis (1964). B. An example gel density profile received with a ChemiDoc ${ }^{\mathrm{TM}}$ MP gel imaging System. C. Mean band volumes ( \pm SE) processed with Image Lab ${ }^{\mathrm{TM}}$ software.

Registration of enzymes dynamics in the apoplast presents a considerable difficulty because the procedures of cell wall purification are susceptible to a loss of soluble proteins from free diffusional space. The vacuum-infiltration method enables extraction of these substances, but it cannot be done repeatedly with the same plant sample. Enzymatic activities released to the incubation medium of cell suspensions are often used to evaluate secretion of enzymes to the extracellular matrix. However, the secretory activity of cells in suspension cultures is not the same as in plant tissues. For instance, suspension-cultured cells release large amount of hydroxyproline-rich glycoproteins, which is not the case with plant tissues. To follow the dynamics of peroxidase secretion to the apolast of elongating maize coleoptiles, we investigated the dynamics of peroxidase release to the incubation medium. The validity of this approach was justified previously by inhibitory analysis using brefeldin A, a specific inhibitor of Golgi-mediated vesicular secretion (Sharova, 2003).

By means of electrophoretic fractionation, peroxidases secreted into the medium were divided into four anionic and three cationic isozymes (Fig. 3A, 4A). The rate of peroxidase secretion gradually increased during incubation of coleoptile segments, but there were no changes in the profile of secreted isozymes. ASC increased the secretion of peroxidases. The effect was ap- 


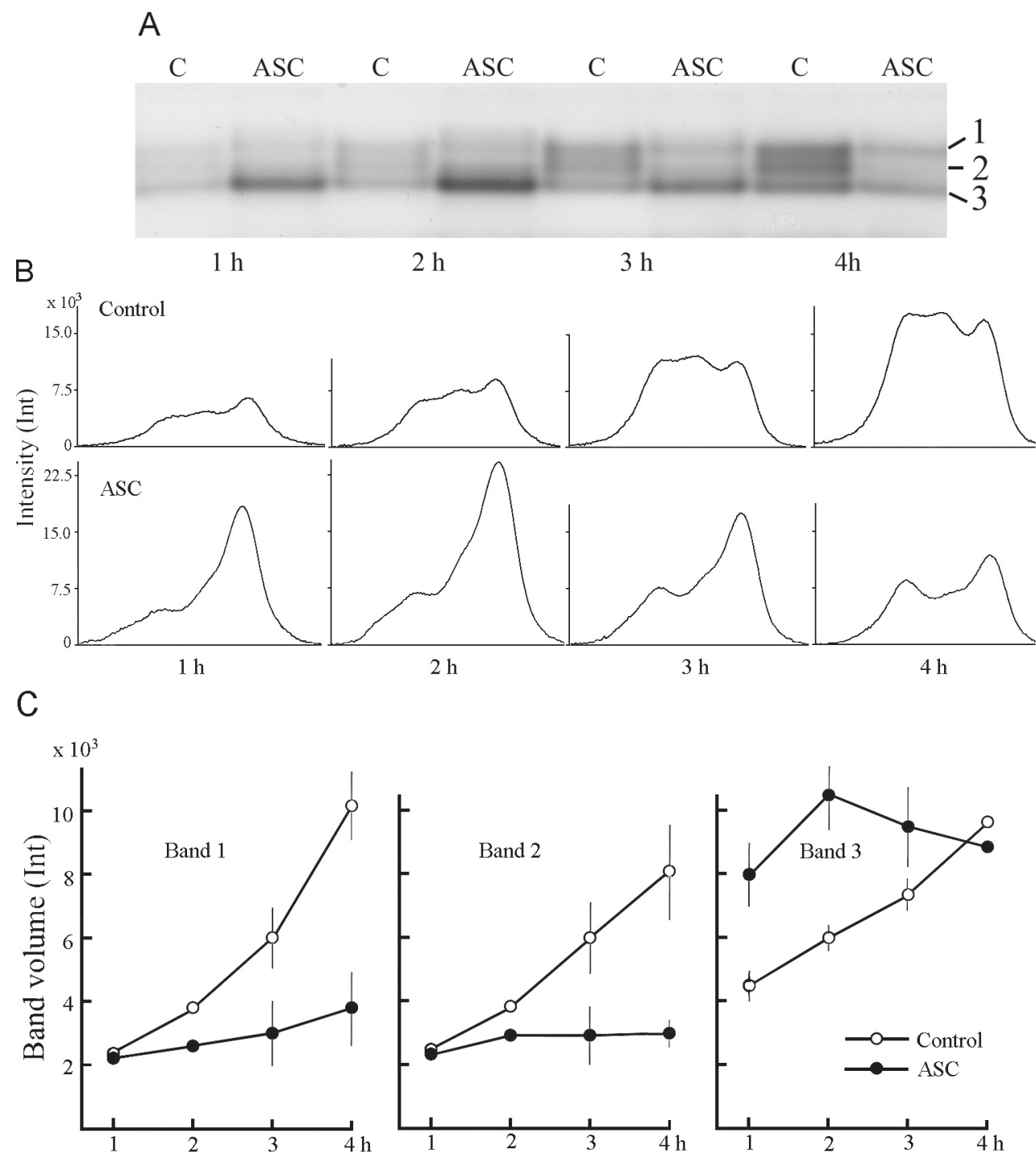

Fig. 4. ASC $(0.3 \mathrm{mM})$ influence on cationic isoperoxidase secretion. A. Peroxidase isozymes revealed in polyacrylamide gels after electrophoresis according to Reisfeld et al. (1962). B. An example gel density profile received with a ChemiDoc ${ }^{\mathrm{TM}} \mathrm{MP}$ gel imaging System. C. Mean band volumes $( \pm \mathrm{SE})$ processed with Image Lab ${ }^{\mathrm{TM}}$ software.

parent already in the first hour of incubation, peaked in the second and third hours and then decreased. Thus, there was a sharp change in the profile of electrophoregrams. ASC caused a five- or six-times increase in the activity of anionic peroxidase 3, a two-times increase in the activity of anionic peroxidase 4 , and a significant decrease in the activity of anionic peroxidases 1 and 2 (Fig. 3). ASC influence on the cationic isozymes was particularly strong and dynamic (Fig. 4). ASC prevented the secretion of cationic isozymes 1 and 2, so that during the fourth hour of incubation the amount of secreted peroxidases was three to four times lower than in the control variant. ASC increased secretion of cationic isozyme 3, but over the time of observation this effect weakened. Thus, as incubation with ASC progressed, the initial activating effect on the cationic isozymes secretion was replaced by a strong inhibitory effect (Fig. 4). The selective effect of ASC on the secretion of various peroxidase isozymes indicates a signal role of this reductant.

\section{THE AXIAL GRADIENT OF CELL ELONGATION IN MAIZE MESOCOTYL}

Maize mesocotyl is one of the classical objects of growth physiology, and the cellular mechanisms of its elongation are thoroughly investigated. The growth of mesocotyl depends on cell divisions in a 1.5-mm-long zone located under the coleoptile node and subsequent elongation of the cells in the zone about $15-20 \mathrm{~mm}$ in length. 


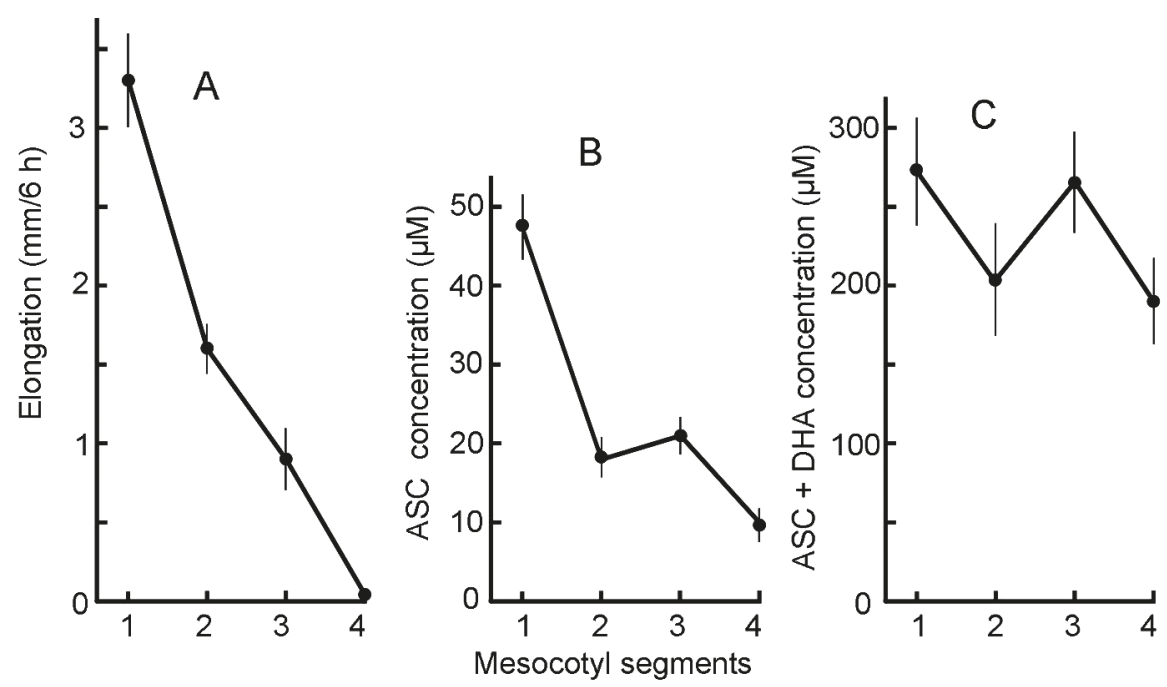

Fig. 5. Concentration of ASC and DHA in apoplastic fluid extracted from maize mesocotyl segments differing in elongation rate. A. Axial profile of elongation rate. B. Concentration of ASC. C. Concentration of ASC+DHA.

The rate of cell elongation rapidly decreased in the basal direction (Fig. 5A). Previously, we have shown that reduction in cell wall extensibility was the main cause of this basipetal growth retardation (Sharova et al, 2012).

\section{CHARACTERISTICS OF OBTAINED APOPLASTIC FLUID}

Apoplastic fluid collected by the method of low-speed centrifugation without preliminary tissue infiltration was essentially free from cytoplasmic components. The activity of the pentose phosphate pathway enzyme glucose 6-phosphate dehydrogenase in the apoplastic fluid isolated from $1 \mathrm{~g}$ of mesocotyls did not exceed $0.02 \%$ of the activity of this enzyme in the homogenate of $1 \mathrm{~g}$ of mesocotyls. Taking into consideration the fact that the volume of apoplastic solution was about $3 \%$ of the volume of homogenate, cytoplasmic contamination did not exceed $0.5 \%$. The volume of apoplastic solution collected from the tissue increased basipetally from $24-28 \mu \mathrm{l} / \mathrm{g}$ fresh wt in the segment 1 to $40-44 \mu \mathrm{l} / \mathrm{g}$ fresh wt in segment 4 , apparently due to the differentiation of xylem vessels.

\section{ASC AND DHA IN APOPLAST OF}

DIFFERENT MESOCOTYL SEGMENTS

To determine the content of ASC, we used ascorbate oxidase. First, we checked that the enzyme rapidly and completely oxidized ASC. Ascorbate oxidase in the chosen concentration $(1.5 \mathrm{U} / \mathrm{ml})$ took only $30 \mathrm{~s}$ to completely oxidize ASC, even at a concentration several times greater than that which was observed in the reaction medium in our experiments $(60-80 \mu \mathrm{M}$ versus $5-10 \mu \mathrm{M})$.
Very large differences in the concentration of reduced ascorbate (ASC) were observed between segments with different growth rates (Fig. 5B). Cell walls of the upper segment contained much more ASC than walls of the second and third segments $(45-50 \mu \mathrm{M}$ versus $20 \mu \mathrm{M})$. And walls of the second and third segments had two times more ASC than walls of the fourth segment $(20 \mu \mathrm{M}$ versus $10 \mu \mathrm{M})$. Thus, rapidly elongating cells (segment 1) had five times more ASC in the apoplast than cells whose elongation was close to the end (segment 4).

The concentration of total oxidized and reduced ascorbate in the apoplast of etiolated maize seedlings was equal to $0.2-0.3 \mathrm{mM}$ (Fig. $5 \mathrm{C}$ ) and fits well in the range of apoplastic ascorbate concentrations described in the scientific literature: $0.1-1 \mathrm{mM}$ (Ueda et al., 2013). We did not find significant differences between segments in the ASC + DHA concentration (Fig. 5C). However, it exhibited a clear "wave": ASC + DHA in segments 1 and 3 was greater than in segments 2 and 4 . The redox state of the apoplastic ascorbate pool (given by [ASC/(ASC + $\mathrm{DHA})] \times 100$ ) was low and gradually decreased in the basal direction from 17 to $5 \%$. Some researchers attach great importance to monodehydroascorbate (MDA) in the regulation of growth (González-Reyes et al., 1995). Media containing both AA and DHA always contain MDA as a product of a spontaneous disproportionation $\mathrm{AA}+\mathrm{DHA} \leftrightarrow 2 \mathrm{MDA}$. The equilibrium of this reaction is strongly shifted leftward $\left(\mathrm{K}_{\mathrm{eq}}=10^{-8}\right)$; hence, MDA concentration never exceeds $0.1 \mu \mathrm{M}$. Defining MDA by calculation, we have shown that its concentration in the apoplast decreased basipetally from $10 \mathrm{nM}$ to $4 \mathrm{nM}$. 


\section{Discussion}

We found only a few publications in which the concentration and redox state of ascorbate in the apoplast were examined in the context of shoot extension growth. In the apoplast of pine hypocotyls, the average sum of ASC + DHA was low, approximately $10 \mu \mathrm{M}(1-4 \mathrm{nmol} / \mathrm{g} \mathrm{FW}$, $0.2-0.4 \mathrm{ml}$ of apolastic fluid was extracted from $1 \mathrm{~g}$ fresh wt by infiltration/centrifugation technique), redox state was high, approximately 75\% (Sanchez et al., 1997). Basipetal growth retardation was accompanied with a fourtimes decrease of the ASC + DHA sum in the apoplast and a moderate decrease in the ascorbate redox state (from 85 to $65 \%$ ).

De Pinto and De Gara (2003) identified 100$400 \mu \mathrm{M}$ of ASC + DHA in the apoplast of etiolated pea shoots, with a very low redox state (5-10\%). Basipetal growth retardation was accompanied with a four-times decrease in the ascorbate sum and a two-times decrease in the ascorbate redox state.

Works performed on isolated segments of adzuki bean epicotyls incubated for 20 hours in an aqueous solution (Takahama, 1994; Takahama, 1994, 1996) stand somewhat apart from the works discussed above. The authors stimulated segments elongation by fusicoccin and auxin, and inhibited it by abscisic acid and light. They also monitored dynamics of endogenous growth changes. Measurement of the apoplastic ASC and DHA content in different conditions showed that growth elevation is usually accompanied with apoplastic ASC + DHA increase and ascorbate redox state decrease.

Obviously, information about the ascorbate redox state optimal for growth is contradictory. In any case, according to reports this index in growing cells does not fall below $10 \%$ and does not rise above $85 \%$. Thus, in the apoplast of growing cells, both ASC and DHA are present in a considerable amount, and hence there is also MDA. All three forms of ascorbate may be important for growth regulation.

Here we found a correlation between the apoplastic ASC and MDA concentration and the growth rate (Fig. 5). It was proposed that MDA radicals stimulate growth because they accept electrons from plasma membrane cytochrome $b$, leading to a multistep energization of the membrane (Gonzalez-Reyes et al., 1995).

ASC in the apoplast can act as an antioxidant and as a pro-oxidant. The manifestation of its pro-oxidant function requires $\mathrm{H}_{2} \mathrm{O}_{2}$ and copper or iron ions. Trace amounts of copper and iron are always present in the cell walls (Fry et al., 2002). We previously showed (Sharova et al., 2012) that the upper mesocotyl segment has the highest level of hydrogen peroxide in the cell walls (Sharova et al., 2012). Thus, in the upper segment there is the highest probability of the Fenton reaction, which generates hydroxyl radical, able to loosen cell walls.
In more detail, we examined the antioxidant role of apoplastic ASC. This role is primarily expressed in the inhibition of PRX-dependent oxidation of phenolic substances (Fig. 2). Apparently, in the rapidly growing mesocotyl segments, the oxidation of phenols incorporated into the cell wall network is suppressed due to the high level of ASC (Fig. 5B) and relatively low potential activity of cell wall peroxidases (Sharova et al., 2012).

We found that the effect of ASC on peroxidases is not limited to the fact that it inhibits the oxidation of phenols. ASC has a highly specific effect on the secretion of different isoforms of peroxidases (Figs. 3, 4), which indirectly indicates its participation in apoplastic redox signaling.

\section{Acknowledgements}

The work was carried out on the equipment of the Research Resource Center for Molecular and Cellular Technologies of Saint Petersburg State University. We are grateful to Alexey Petrovich Voronin and Arsenij A. Lobov, specialists of the center, for their help in work on ChemiDoc ${ }^{\mathrm{TM}}$ MP gel imaging System with Image Lab ${ }^{\text {TM }}$ software and NanoPhotometer IMPLEN P300.

Abbreviations: ASC — ascorbic acid; DHA — didehydroascorbic acid; PRX - guaiacol peroxidase; ROS - reactive oxygen species; MDA - monodehydroascorbic acid.

\section{References}

Cordoba-Pedregosa, M.C., Gonzalez-Reyes, J.A., Cañadillas, M. S., Navas, P., and Cordoba, F. 1996. Role of apoplastic and cell-wall peroxidases on the stimulation of root elongation by ascorbate. Plant Physiology 112:11191125. https://doi.org/10.1104/pp.112.3.1119

Cordoba-Pedregosa, M. C., Cordoba, F., Villalba, J. M., and Gonzalez-Reyes, J. A. 2003. Zonal changes in ascorbate and hydrogen peroxide contents, peroxidase, and ascorbate-related enzyme activities in onion roots. Plant Physiology 131:697-706. https://doi.org/10.1104/pp.012682

Cosio, C., and Dunand, C. 2009. Specific functions of individual class III peroxidase genes. Journal of Experimental Botany 60:391-408. https://doi.org/10.1093/jxb/ern318

Davis, B.J. 1964. Disc electrophoresis. II. Method and application to human serum proteins. Annals of the New York Academy of Science 121:404-427. https://doi. org/10.1111/j.1749-6632.1964.tb14213.x

De Pinto, M. C., and De Gara, L. 2004. Changes in the ascorbate metabolism of apoplastic and symplastic spaces are associated with cell differentiation. Journal of Experimental Botany 55:2559-2569. https://doi.org/doi:10.1093/jxb/ erh253

De Tullio, M., Guether, M., and Balestrini, R. 2013. Ascorbate oxidase is the potential conductor of a symphony of signaling pathways. Plant Signaling and Behavior 8:375-384. https://doi.org/10.4161/psb.23213

Dragisic-Maksimovic, J., Maksimovic, V., Zivanovic, B., HadziTaskovic-Sukalovic, V., and Vuletic, M. 2008. Peroxidase activity and phenolic compounds content in maize root and leaf apoplast, and their association with growth. Plant Science 175:656-662. https://doi.org/10.1016/j. plantsci.2008.06.015 
Francoz, E., Ranocha, P., Nguyen-Kim, H., Jamet, E., Burlat, V., and Dunand, C. 2015. Roles of cell wall peroxidases in plant development. Phytochemistry 112:15-21. https:// doi.org/10.1016/j.phytochem.2014.07.020

Fry, S. C., Miller, J. G., and Dumville, J.C. 2002. A proposed role for copper ions in cell wall loosening. Plant and Soil 247:57-67. https://doi.org/10.1023/A:1021140022082

Hadzi-Taskovic-Sukalovic, V., Vuletic, M., Vucinic, Z., and Veljovic-Jovanovic, S. 2008. Effectiveness of phenoxyl radicals generated by peroxidase $/ \mathrm{H}_{2} \mathrm{O}_{2}$-catalyzed oxidation of caffeate, ferulate, and p-coumarate in cooxidation of ascorbate and NADH. Journal of Plant Research 121:115123. https://doi.org/10.1007/s10265-007-0124-x

Heyno, E., Mary, V., Schopfer, P., and Krieger-Liszkay, A. 2011. Oxygen activation at the plasma membrane: relation between superoxide and hydroxyl radical production by isolated membranes. Planta 234:35-45. https://doi. org/10.1007/s00425-011-1379-y

Gonzalez-Reyes, J.A., Alcain, F.J., Caler, J.A., Serrano, A., Cordoba, F., and Navas, P. 1995. Stimulation of onion root elongation by ascorbate and ascorbate free radical in Allium cepa L. Protoplasma 184:31-35. https://doi. org/10.1007/BF01276898

Kato, N., and Esaka, M. 1999. Changes in ascorbate oxidase gene expression and ascorbate levels in cell division and cell elongation in tobacco cells. Physiologia Plantarum 105:321-329. https://doi.org/10.1034/j.13993054.1999.105218.X

Kisu, Y., Harada, Y., Goto, M., and Esaka, M. 1997. Cloning of the pumpkin ascorbate oxidase gene and analysis of a cis-actin region involved in induction by auxin. Plant and Cell Physiology 38:631-637. https://doi.org/10.1034/ j.1399-3054.1999.105218.x

Kukavica, B., Mojovic, M., Vucinic, Z., Maksimovic, V., Takahama, U., and Veljovic-Jovanovic, S. 2009. Generation of hydroxyl radical in isolated pea root cell wall, and the role of cell wall-bound peroxidase, Mn-SOD and phenolics in their production. Plant and Cell Physiology 50:304-317. https://doi.org/10.1093/pcp/pcn199

Lee, Y., Park, C.H., Kim, A.R., Chang, S.C., Kim, S.-H., Lee, W.S., and Kim, S.-K. 2011. The effect of ascorbic acid and dehydroascorbic acid on the root gravitropic response in Arabidopsis thaliana. Plant Physiology and Biochemistry 49:909-916. https://doi.org/10.1016/j.plaphy.2011.05.013

Mei, W., Qin, Y., Song, W., Li, J., and Zhu, Y. 2009. Cotton GhPOX1 encoding plant class III peroxidase may be responsible for the high level of reactive oxygen species production that is related to cotton fiber elongation. Journal of Genetics and Genomics 36:141-150. https://doi. org/10.1016/S1673-8527(08)60101-0

Padu, E. 1999. Apoplastic peroxidases, ascorbate and lignification in relation to nitrate supply in wheat stem. Journal of Plant Physiology 154:576-583. https://doi.org/10.1104/ pp.106.1.53

Passardi, F., Tognolli, M., de Meyer, M., Penel, C., and Dunand, C. 2006. Two cell wall associated peroxidases from Arabidopsis influence root elongation. Planta 223:965974. https://doi.org/10.1007/s00425-005-0153-4

Pignocchi, C., and Foyer, C. H. 2003. Apoplastic ascorbate metabolism and its role in the regulation of cell signaling. Current Opinion in Plant Biology 6:379-389. https://doi. org/10.1016/S1369-5266(03)00069-4

Qian, H. F., Peng, X. F., Han, X., Ren, J., Zhan, K. Y., and Zhu, M. 2014. The stress factor, exogenous ascorbic acid, affects plant growth and the antioxidant system in Arabidopsis thaliana. Russian Journal of Plant Physiology 61:467-475. https://doi.org/10.1134/S1021443714040141
Reisfeld, R. A., Lewis, U. J., and Williams, D. E. 1962. Disk electrophoresis of basic proteins and peptides on polyacrylamide gels. Nature 195:281-283. https://doi. org/10.1038/195281a0

Sánchez, M., Queijeiro, E., Revilla, G., and Zarra, I. 1997. Changes in ascorbic acid levels in apoplastic fluid during growth of pine hypocotyls. Effect on peroxidase activities associated with cell walls. Physiologia Plantarum 101:815-820. https://doi.org/10.1111/j.1399-3054.1997. tb01068.x

Schopfer, P. 2001. Hydroxyl radical-induced cell wall loosening in vitro and in vivo: implications for the control of elongation growth. Plant Journal 28:679-688. https://doi. org/10.1046/j.1365-313x.2001.01187.x

Sharova, E. I. 2003. Cell wall extensibility changes by hormonal and non-hormonal factors; pp. 185-191 in Machackova, I., and Romanov G. A. (eds), Phytohormones in plant biotechnology and agriculture. Kluwer Ac. Publishers, Dordrecht. https://doi.org/10.1007/978-94-017-26641_16

Sharova, E. I. 2004. Kletochnaya stenka rastenii [The plant cell wall.] 153 pp. Izdatelstvo Sankt-Peterburgskogo Universiteta, Saint Petersburg.

Sharova, E. I. 2016. Antioxidanty rastenij [Plant antioxidants.] 140 pp. Izdatelstvo Sankt-Peterburgskogo Universiteta, Saint Petersburg.

Sharova, E. I., Bilova, T.E., and Medvedev, S. S. 2012. Axial changes in apoplast properties in the elongation zone of maize mesocotyl. Russian Journal of Plant Physiology 59:565-572. https://doi.org/10.1134/ S1021443712040139

Sharova, E. I., and Medvedev, S. S. 2017. Redox reactions in apoplast of growing cells. Russian Journal of Plant Physiology 64:3-18. https://doi.org/10.1134/S1021443717010149

Shigeto, J., Nagano, M., Fujita, K., and Tsutsumi, Y. 2014. Catalytic profile of Arabidopsis peroxidases, AtPrx-2, 25 and 71, contributing to stem lignification. PLoSOne 9:e105332. https://doi.org/10.1371/journal.pone.0105332

Takahama, U. 1993. Regulation of peroxidase-dependent oxidation of phenolics by ascorbic acid: different effects of ascorbic acid on the oxidation of coniferyl alcohol by the apoplastic soluble and cell wall-bound peroxidases from epicotyls of Vigna angularis. Plant and Cell Physiology 34:809-817. https://doi.org/10.1093/oxfordjournals. pсp.a078488

Takahama, U. 1994. Changes induced by abscisic acid and light in the redox state of ascorbate in the apoplast of epicotyls of Vigna angularis. Plant and Cell Physio/ogy 35:975-978. https://doi.org/10.1093/oxfordjournals. pсp.a078685

Takahama, U. 1996. Effects of fusicoccin and indole-3-acetic acid on the levels of ascorbic acid and dehydroascorbic acid in the apoplast during elongation of epicotyl segments of Vigna angularis. Physiologia Plantarum 98:731-736. https://doi.org/10.1111/j.1399-3054.1996. tb06678.x

Takahama, U., and Oniki, T. 1994. The association of ascorbate and ascorbate oxidase in the apoplast with IAAenhanced elongation of epicotyls from Vigna angularis. Plant and Cell Physiology 35:257-266. https://doi. org/10.1093/oxfordjournals.pcp.a078591

Tyburski, J., Dunajska-Ordak, K., Skorupa, M., and Tretyn, A. 2012. Role of ascorbate in the regulation of the Arabidopsis thaliana root growth by phosphate availability. Journal of Botany. Article ID 580342. https://doi. org/10.1155/2012/580342

Uddin, M. N., Hanstein, S., Faust, F., Eitenmüller, P. T., Pitann, B., and Schubert, S. 2014. Diferulic acids in the 
cell wall may contribute to the suppression of shoot growth in the first phase of salt stress in maize. Phytochemistry 102:126-136. https://doi.org/10.1016/j.phytochem.2014.02.014

Ueda, Y., Wu, L., and Frei, M. 2013. A critical comparison of two high-throughput ascorbate analyses methods for plant samples. Plant Physiology and Biochemistry 70:418423. https://doi.org/10.1016/j.plaphy.2013.06.006
Zhu, J., Alvarez, S., Marsh, E. L., LeNoble, M. E., Cho, I.J., Sivaguru, M., Chen, S., Nguyen, H. T., Wu, Y., Schachtman, D. P., and Sharp, R. E. 2007. Cell wall proteome in the maize primary root elongation zone. II. Region-specific changes in water soluble and lightly ionically bound proteins under water deficit. Plant Physiology 145:1533-1548. https://doi.org/10.1104/ pp.107.107250 